\title{
Coagonist Release Modulates NMDA Receptor Subtype Contributions at Synaptic Inputs to Retinal Ganglion Cells
}

\author{
Trisha L. Kalbaugh, Jun Zhang, and Jeffrey S. Diamond \\ Synaptic Physiology Section, National Institute of Neurological Disorders and Stroke, National Institutes of Health, Bethesda, Maryland 20892-3701
}

\begin{abstract}
NMDA receptors (NMDARs) are tetrameric protein complexes usually comprising two NR1 and two NR2 subunits. Different combinations of four potential NR2 subunits (NR2A-D) confer diversity in developmental expression, subsynaptic localization, and functional characteristics, including affinity for neurotransmitter. NR2B-containing NMDARs, for example, exhibit relatively high affinity both for glutamate and the coagonist glycine. Although multiple NMDAR subtypes can colocalize at individual synapses, particular subtypes often mediate inputs from distinct functional pathways. In retinal ganglion cells (RGCs), NMDARs contribute to synaptic responses elicited by light stimulus onset ("ON") and offset ("OFF"), but roles for particular NMDAR subtypes, and potential segregation between the $\mathrm{ON}$ and OFF pathways, have not been explored. Moreover, elements in the retinal circuitry release two different NMDAR coagonists, glycine and D-serine, but the effects of endogenous coagonist release on the relative contribution of different NMDAR subtypes are unclear. Here, we show that coagonist release within the retina modulates the relative contribution of different NMDARs in the ON pathway of the rat retina. By pharmacologically stimulating functional pathways independently in acute slices and recording synaptic responses in RGCs, we show that ON inputs, but not OFF inputs, are mediated in part by NMDARs exhibiting NR2B-like pharmacology. Furthermore, suppressing release of NMDAR coagonist reduces NMDAR activation at $\mathrm{ON}$ synapses and increases the relative contribution of these putative NR2Bcontaining receptors. These results demonstrate direct evidence for evoked coagonist release onto NMDARs and indicate that modulating coagonist release may regulate the relative activation of different NMDAR subtypes in the ON pathway.
\end{abstract}

Key words: NMDA receptor; AMPA receptor; glycine; retinal ganglion cell; retinal bipolar cell; synaptic transmission; retina

\section{Introduction}

Activation of NMDA receptors (NMDARs) requires coincident binding of glutamate and a coagonist, which can be either glycine (Johnson and Ascher, 1987) or D-serine (Mothet et al., 2000). Although the coagonist binds the two NR1 subunits in the NMDAR tetramer (Lynch et al., 1994), the identity of the NR2 subunits (NR2A-D) determines affinity for both the coagonist and glutamate (Dingledine et al., 1999). NMDARs expressing different NR2 subunits can colocalize within a synapse (Tovar and Westbrook, 1999); because NMDARs may not be saturated by synaptic levels of glutamate (Mainen et al., 1999; Ishikawa et al., 2000; McAllister and Stevens, 2000) or coagonist (Vyklický et al., 1990; Wilcox et al., 1996; Panatier et al., 2006), higher-affinity subtypes within a mixed population may be activated preferentially during synaptic transmission. Accordingly, mechanisms that regulate available concentrations of transmitter could change the relative contributions of NMDAR subtypes to synaptic signaling.

\footnotetext{
Received Sept. 2, 2008; revised Dec. 31, 2008; accepted Jan. 2, 2009.

This work was supported by the National Institute of Neurological Disorders and Stroke Intramural Research Program and a National Institute of General Medical Sciences Pharmacology Research Associate Fellowship to T.L.K. We thank David Paul for generously providing $\mathrm{Cx} 36-1-$ mice, Hua Tian for technical assistance with mouse genotyping, and Will Grimes, Christopher Thomas, and Annalisa Scimemi for helpful comments on this manuscript

Correspondence should be addressed to Dr. Jeffrey S. Diamond, Synaptic Physiology Section, National Institute of Neurological Disorders and Stroke/National Institutes of Health, 35 Convent Drive, Building 35, Room 3C-1000, Bethesda, MD 20892-3701. E-mail: diamondj@ninds.nih.gov.

D01:10.1523/JNEUROSCI.4240-08.2009

Copyright $\odot 2009$ Society for Neuroscience $\quad$ 0270-6474/09/291469-11\$15.00/0
}

In the retina, NMDARs on ganglion cells (RGCs) are activated by glutamate released from cone bipolar cells (CBCs) in spatially segregated ON and OFF pathways (Mittman et al., 1990; Sagdullaev et al., 2006). All four NR2 subunits are expressed in vertebrate retina (Brandstätter et al., 1994; Watanabe et al., 1994; Gründer et al., 2000), and both NR2A and NR2B are prevalent in the inner plexiform layer (IPL) (Fletcher et al., 2000), where NMDARs are localized on RGC dendrites (Grünert et al., 2002), but it remains unknown how different NMDAR subtypes contribute to RGC synaptic responses. ON and OFF inputs could express distinct NMDAR subtypes, similar to other neurons receiving input from multiple pathways (Kawakami et al., 2003; Kumar and Huguenard, 2003; Arrigoni and Greene, 2004). Alternatively, NMDARs at these inputs might have differential access to glutamate (Sagdullaev et al., 2006) or the coagonist (Lukasiewicz and Roeder, 1995), the identity (glycine vs D-serine) of which remains uncertain. Several types of amacrine cells provide inhibitory glycinergic input to RGCs (Kolb, 1979; Menger et al., 1998), but whether this glycine reaches spatially segregated excitatory synapses, and whether ambient glycine levels saturate NMDARs, is unclear. D-Serine, present in Müller glia (Stevens et al., 2003), also may contribute to NMDAR activation in the retina (Gustafson et al., 2007).

To investigate how coagonist levels and NMDAR subunit composition interact to regulate NMDAR activation on RGCs, we recorded EPSCs from RGCs in acute slices of rat retina. We find that a significant fraction of synaptically activated NMDARs 
in the ON pathway, but not the OFF pathway, are sensitive to an NR2B NMDARselective antagonist. Within the ON pathway, the relative contribution of NR2Bcontaining NMDARs to the EPSC is modulated by coagonist release, and synaptic stimulation can increase coagonist levels from subsaturating to saturating concentrations. Together, these results demonstrate an important role for coagonist release in regulating the synaptic activation of different NMDAR subtypes on RGCs.

\section{Materials and Methods}

Slice preparation and solutions. Acute retinal slices were prepared from Sprague Dawley rats and transgenic mice (17-23 d) in accordance with the guidelines of the National Institute of Neurological Disorders and Stroke Animal Care and Use Committee, as described previously (Chen and Diamond, 2002). Following anesthesia and decapitation, both eyes were removed and immersed in oxygenated extracellular solution at room temperature. Extracellular solution contained (in $\mathrm{mM}$ ): $119 \mathrm{NaCl}, 2.5 \mathrm{KCl}$, $1.5 \mathrm{MgCl}_{2}, 2.5 \mathrm{CaCl}_{2}, 1.25 \mathrm{NaH}_{2} \mathrm{PO}_{4}, 24$ $\mathrm{NaHCO}_{3}, 10$ glucose, $2 \mathrm{Na}$ pyruvate, and $2 \mathrm{Na}$ lactate, bubbled with $95 \% \mathrm{O}_{2}$ and $5 \% \mathrm{CO}_{2}$. Following surgical isolation of the retina, a small piece was embedded in $2 \%$ agarose and cut into $200-\mu \mathrm{m}$-thick slices on a Vibratome 3000 (Ted Pella). From the storage chamber, slices were transferred one at a time to the recording chamber, which was perfused continuously (1.5-2 $\mathrm{ml} / \mathrm{min}$ ) with oxygenated extracellular solution supplemented with picrotoxin $(100 \mu \mathrm{M})$, TPMPA $(50 \mu \mathrm{M})$, and strychnine $(10 \mu \mathrm{M})$ to block inhibitory synaptic transmission (except as noted). Control extracellular solution also contained the group III mGluR agonist L-AP4 (10 $\mu \mathrm{M}$; except in light stimulation experiments), and $0.3 \mu \mathrm{M}$ TTX was included to block voltage-gated sodium $\left(\mathrm{Na}_{\mathrm{v}}\right)$ channels. In experiments requiring the reduction of extracellular $\left[\mathrm{Ca}^{2+}\right], \mathrm{CaCl}_{2}$ was replaced with equimolar $\mathrm{MgSO}_{4}$. The patch pipette solution contained (in $\mathrm{mm}$ ): 90 Cs methanesulfonate, $20 \mathrm{TEA}-\mathrm{Cl}$, 10 HEPES, 10 EGTA, 10 sodium phosphocreatine, $2 \mathrm{MgATP}$, and $0.2 \mathrm{NaGTP}$, adjusted to $\mathrm{pH} 7.35$ with $\mathrm{CsOH}$. All experiments were performed at room temperature $\left(22^{\circ} \mathrm{C}\right)$, except light stimulation experiments, in which extracellular solution was warmed to $26^{\circ} \mathrm{C}$ by an inline heater. Reagents were obtained from Sigma (all salts, picrotoxin, strychnine, TPMPA, and DAAO), Tocris Cookson (all modulators of glutamate receptors), and Alomone (TTX).

Cell identification. RGCs were selected on the basis of location in the ganglion cell layer, large somata, and input resistances between 100 and $600 \mathrm{M} \Omega$. Identification of AII amacrine cells, rod bipolar cells, and ON cone bipolar cells was aided by the addition of Alexa 488 ( $10 \mu \mathrm{M}$; Molecular Probes) to the pipette solution and fluorescent imaging of the cells, which exhibited distinct patterns of dendritic ramification in the inner plexiform layer (Singer and Diamond, 2003; Chávez and Diamond, 2008).
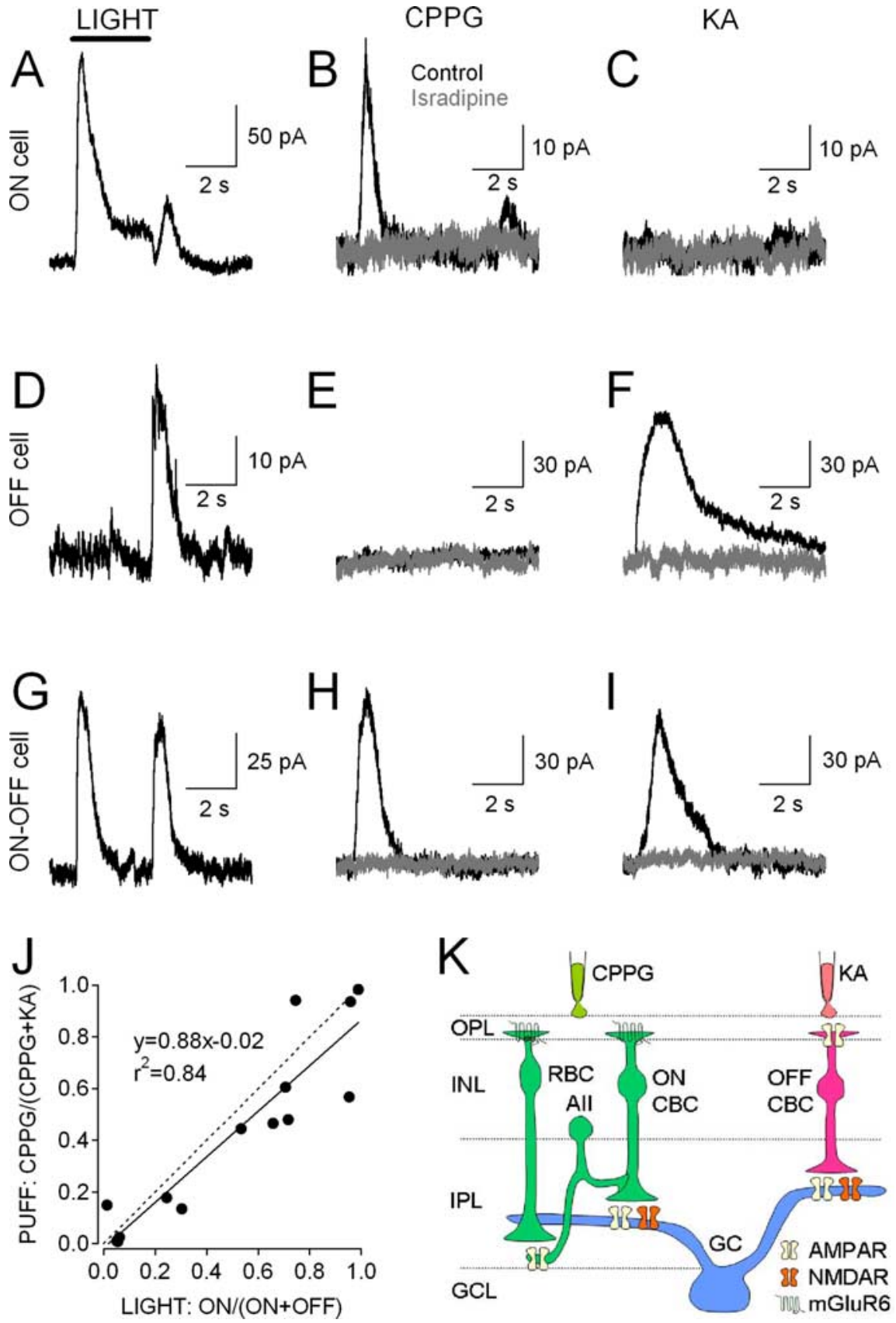

Figure 1. EPSCS elicited by light and pharmacological stimulation of ON and OFF bipolar cells. A-I, Responses from three different RGCs elicited by three kinds of stimulation: a $3 \mathrm{~s}$, full-field light stimulus at an intensity of $10^{3}-10^{4}$ photons $/ \mu \mathrm{m}^{2} / \mathrm{s}(\boldsymbol{A}$, $\boldsymbol{D}, \boldsymbol{G})$; pressure application of $\mathrm{CPPG}(600 \mu \mathrm{M}, 240 \mathrm{~ms})$ in the OPL $(\boldsymbol{B}, \boldsymbol{E}, \boldsymbol{H})$; and pressure application of KA (100 $\mu \mathrm{M}, 140 \mathrm{~ms})$ in the OPL $(\boldsymbol{C}, \boldsymbol{F}, \boldsymbol{I})$. Responses were recorded from ON $(\boldsymbol{A}-\boldsymbol{C})$, OFF $(\boldsymbol{D}-\boldsymbol{F})$, and ON-OFF $(\boldsymbol{G}-\boldsymbol{I}) \mathrm{RGCS}$. Puff-evoked responses were blocked by the L-type $C_{\mathrm{v}}$ channel antagonist isradipine ( $10 \mu \mathrm{m}$, gray traces), indicating that they required synaptic transmission. $V_{\text {hold }}=$ $+40 \mathrm{mV}$ for all EPSCS. J, Correlation between light responses ( $x$-axis) and puff responses ( $y$-axis). EPSC charge transfer ( $\left.Q_{\text {EPSC }}\right)$ was calculated for $3 \mathrm{~s}$ windows following light onset and light offset and from the time of CPPG or KA puff stimulation until the EPSC amplitude returned to $5 \%$ of its peak value. $x$ values represent $0 \mathrm{~N}$ light-evoked $Q_{\text {EPSC }}$ as a fraction of total (ON $\left.+0 \mathrm{FF}\right)$ light-evoked $Q_{\text {EPSC }}$, while $y$ values represent $C P P G Q_{\text {EPSC }}$ as a fraction of total (CPPG $\left.+K A\right) Q_{\text {EPSC }}$. Filled symbols denote individual cells $(n=14)$, the solid line shows linear regression, and the dashed line represents unity. $\boldsymbol{K}$, Schematic of retinal circuit showing parallel ON and OFF pathways activated by CPPG and KA, respectively.

Electrophysiology. All recordings were made with an Axopatch 1D amplifier (Axon Instruments) in voltage-clamp mode. Patch electrodes (\#0100 glass; World Precision Instruments) had tip resistances of 4-6 $\mathrm{M} \Omega$ when filled with internal solution. Access resistance (15-30 M $\Omega$ ) was monitored constantly and not compensated. Data acquisition and analysis were performed with custom macros written in Igor Pro (Wavemetrics). Data were filtered at $1 \mathrm{kHz}$ and sampled at $2 \mathrm{kHz}$. 

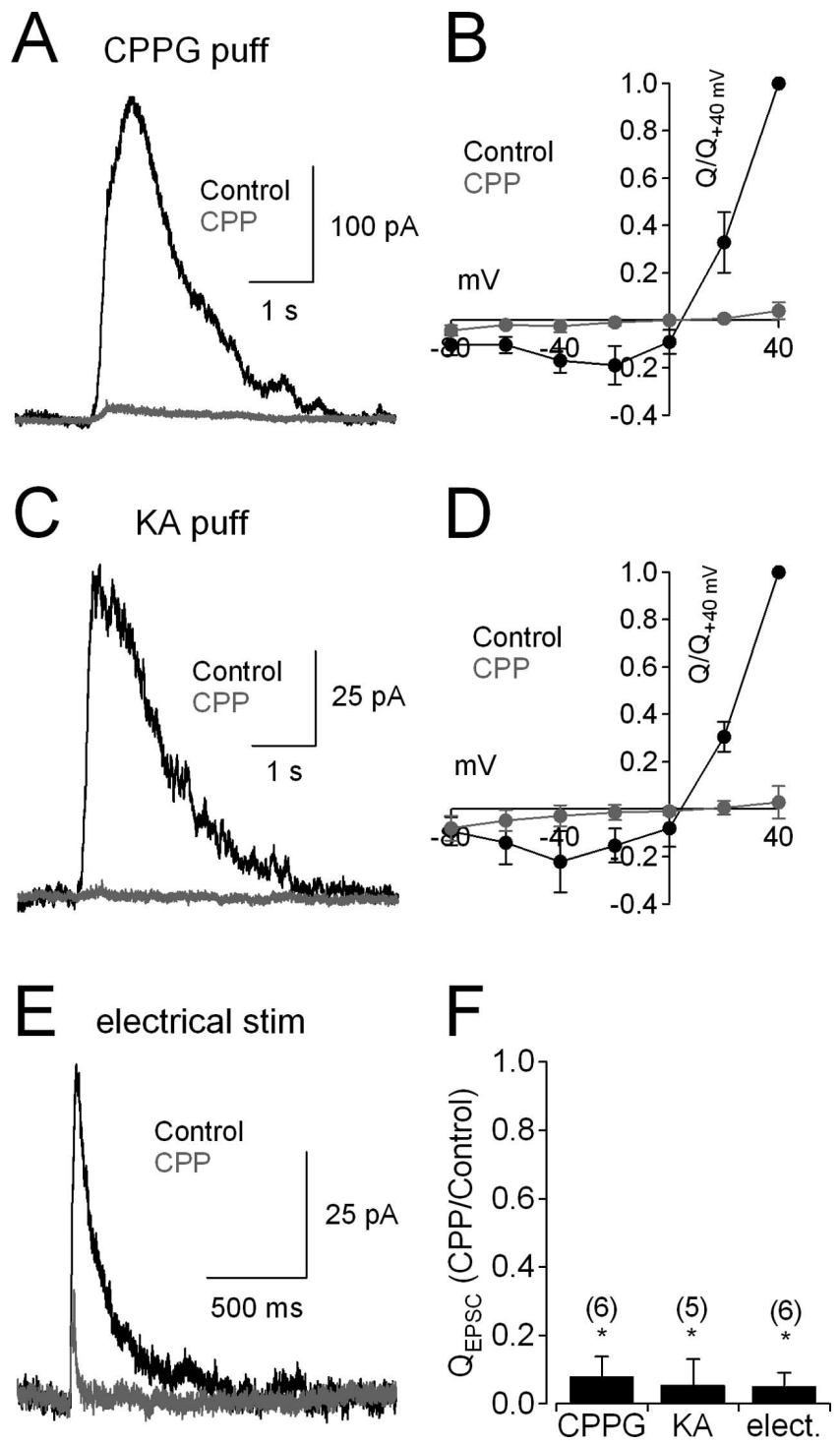

Figure 2. RGC EPSCS are mediated primarily by NMDARs. A, CPPG-evoked ("ON") EPSCS recorded from RGCs $\left(V_{\text {hold }}=+40 \mathrm{mV}\right)$ are blocked almost completely by the NMDAR antagonist $R, S$-CPP (10 $\mu \mathrm{m}$, gray trace). B, ON EPSCs exhibited the J-shaped charge-voltage relationship that is characteristic of NMDARs; the small, CPP-insensitive component exhibited an ohmic (linear) conductance (gray symbols). For each cell, data points were normalized to the control $Q_{\text {EPSC }}$ recorded at $+40 \mathrm{mV}$. C, $\boldsymbol{D}$, As in $\boldsymbol{A}$ and $\boldsymbol{B}$, but EPSCS were elicited by KA. $\boldsymbol{E}$, Electrically evoked EPSCs were recorded from the same cells as shown in $\boldsymbol{C}$. $\boldsymbol{F}$, Fraction of $Q_{\text {EPSC }}$ remaining in the presence of CPP compared across stimulation modalities (KA puff, CPPG puff, electrical stimulation). $n$ values are indicated in parentheses.

Light stimulation. Slices were prepared under dim red light. Voltage steps were used to illuminate an LED mounted on the top port of a Zeiss inverted microscope. Full-field illumination was focused orthogonally to the main axis of the photoreceptors. Stimulus intensities were typically $10^{3}-10^{4}$ photons $/ \mathrm{mm}^{2} / \mathrm{s}$, and $3 \mathrm{~s}$ stimuli were given at $30 \mathrm{~s}$ intervals.

Pressure application of CPPG and kainic acid. A pneumatic pump (Parker Hannifin) at 4-9 psi was used to apply CPPG $(600 \mu \mathrm{M})$ or kainic acid (KA) $(100 \mu \mathrm{M})$ from a glass pipette positioned in the outer plexiform layer. In some experiments, CPPG and KA were loaded into separate sides of a theta glass pipette; independent application of either compound was confirmed by the failure of CPPG, applied directly to the RGC soma, to produce a response, while direct application of KA to the same cell produced an excitatory response (data not shown). Stimuli (100-300 $\mathrm{ms}$ ) were delivered at $30 \mathrm{~s}$ intervals.

Electrical stimulation. Responses were elicited at $30 \mathrm{~s}$ intervals with a stainless-steel bipolar electrode (Frederick Haer) positioned in the outer plexiform layer.

Immunohistochemistry. Tissue was prepared for light microscopy as described previously (Zhang and Diamond, 2006). Briefly, eyecups from P17 and P22 animals were fixed (D-serine: $4 \%$ paraformaldehyde, $0.5 \%$ glutaraldehyde, $0.2 \%$ sodium metabisulfite; serine racemase (SR): $4 \%$ paraformaldehyde) in $0.1 \mathrm{M}$ phosphate buffer (PB) at $\mathrm{pH} 7.4$ for 15-30 min at room temperature. Eyecups were washed several times in $0.1 \mathrm{M}$ PBS, pH 7.4 , with $0.5 \%$ sodium borohydride and $0.2 \%$ sodium metabisulfite, then cryoprotected at $4^{\circ} \mathrm{C}$ with graded sucrose solutions $(15 \%$, $20 \%$, and $30 \%, 60$ min each; then overnight in $30 \%$ ). The tissue was vertically sectioned ( $20 \mu \mathrm{m}$ thick) on a cryostat, and mounted on glass slides. Slides were rinsed in PBS, blocked in 10\% normal donkey serum (NDS, Sigma) in PBS for $1 \mathrm{~h}$ and incubated overnight in primary antibodies of either polyclonal anti-rabbit D-serine (1:200, Gemac), polyclonal anti-goat SR (1:100, Gemac), or a mixture of monoclonal antimouse glutamine synthetase (1:300, Chemicon) with D-serine or SR in $2 \%$ NDS plus $1 \%$ bovine serum albumin (BSA, Sigma) with $0.3 \%$ Triton $\mathrm{X}-100$ at $4^{\circ} \mathrm{C}$. Sections were rinsed and incubated for $2 \mathrm{~h}$ at room temperature in Cy3-conjugated donkey anti-rabbit IgG or anti-goat IgG (1:400) or FITC-conjugated anti-mouse IgG (1:400; all from Jackson ImmunoResearch Laboratories). Immunofluorescence was visualized with a confocal laser scanning microscope (Zeiss LSM-510) through a $25 \times, 0.9$ NA objective. Image brightness and contrast were adjusted in Adobe Photoshop 6.0.

Antibodies used in this study have been characterized previously in rodent retina by Western blot and immunocytochemistry (Stevens et al. 2003; Dun et al., 2008). The specificity of D-serine and SR antibodies was verified with preadsorption experiments. When polyclonal antibodies to D-serine and SR were preadsorbed with D-serine or polypeptide antigen, respectively (both from Gemac), no fluorescence was detected (see Fig. $7 A 3, B 2, C 3, D 2)$. D-Serine immunoreactivity was unaffected by attempted preadsorption with L-serine (see Fig. 7A4,C4). Additionally, single or double labeling always was accompanied by negative control experiments in which one or two primary antibodies were eliminated and then the one or two appropriate secondary antibodies were applied in single or double labeling. In these cases, only fluorescence specific for the remaining primary antibody was detected (data not shown).

Statistical analysis. Unless otherwise indicated, all data are expressed as mean $\pm \mathrm{SD} ; p$ values indicate paired or unpaired $t$ tests, as appropriate (and noted), and $p<0.05$ was considered significant.

\section{Results}

\section{Light responses predict synaptic responses to puff application} of CPPG and KA

Acute retinal slices permit physiological stimulation of the circuitry with light (Werblin, 1978), but interpreting pharmacological effects on light responses in the inner retina is complicated by potentially confounding actions in the outer retina. To reduce this problem, we bypassed photoreceptors by stimulating $\mathrm{ON}$ and OFF bipolar cells directly in acute slices of rat and mouse retina with focal pressure ("puff") application of exogenous agents in the outer plexiform layer (OPL) (Fig. $1 \mathrm{~K}$ ). ON bipolar cells [rod bipolar cells (RBCs) and ON cone bipolar cells (ON CBCs)] were depolarized by puff application of the group II/III mGluR antagonist CPPG $(600 \mu \mathrm{M}, 240 \mathrm{~ms})$ in the continuous presence of the group III mGluR agonist L-AP4 (10 $\mu \mathrm{M})$ (Nawy, 2004; Chávez et al., 2006). OFF cone bipolar cells (OFF CBCs) were depolarized by puff application of the AMPA/KA receptor (AMPAR/KAR) agonist KA (100 $\mu \mathrm{M}, 140 \mathrm{~ms})$. Inhibitory neurotransmission and $\mathrm{Na}_{\mathrm{v}}$ channels were blocked in all experiments (see Materials and Methods).

To confirm that synaptic responses in RGCs to CPPG and KA accurately represented the relative contributions of $\mathrm{ON}$ and $\mathrm{OFF}$ synaptic inputs, sensitivity to light and puff stimulation was compared within individual RGCs. EPSCs, recorded from RGCs under whole-cell voltage clamp $\left(V_{\text {hold }}=+40 \mathrm{mV}\right)$, were evoked by 
full-field light stimuli $\left(3 \mathrm{~s}, 10^{3}-10^{4}\right.$ photons $/ \mu \mathrm{m}^{2} / \mathrm{s}$ ). Then, following addition of L-AP4 $(10 \mu \mathrm{M})$ to the bath solution, EPSCs were elicited by brief applications of CPPG and KA delivered to the OPL through a double-barreled pipette. RGCs that responded strongly to the onset of a light stimulus, but not to its offset ("ON cells"), responded to puff application of CPPG, but not KA (Fig. 1A-C). Conversely, RGCs that responded strongly to light offset, but not onset ("OFF cells"), responded to pressure application of KA but not CPPG (Fig. $1 D-F$ ). A third group of cells responded strongly to both light onset and offset ("ON-OFF cells") and also responded well to both CPPG and KA (Fig. $1 G-I)$. CPPG and KA responses were reduced almost completely by the L-type voltage-gated calcium $\left(\mathrm{Ca}_{\mathrm{v}}\right)$ channel blocker isradipine [CPPG: charge transfer $\left(Q_{\mathrm{EPSC}}\right)$ reduced to $10 \pm 10 \%$ of control; $n=14 ; p=0.002$; KA: $Q_{\text {EPSC }}$ reduced to $20 \pm 3 \%$ of control; $n=14 ; p=0.0003$ ] (Fig. 1), indicating that puff-evoked currents reflect primarily synaptic release from bipolar cells, rather than direct activation of RGCs. Given the strong agreement between ON/OFF light and CPPG/KA puff responsivity (Fig. 1J), CPPG-evoked and KAevoked synaptic currents will be referred to here as "ON EPSCs" and "OFF EPSCs," respectively.

ON and OFF EPSCs in RGCs are primarily NMDAR mediated During an evoked response, glutamate released from bipolar cells activates both AMPARs and NMDARs on RGCs (Mittman et al., 1990; Matsui et al., 1998; Chen and Diamond, 2002). More recent work suggests that transmitter release and NMDAR activation may be regulated differently at ON and OFF RGC synapses (Sagdullaev et al., 2006). To compare NMDAR EPSCs activated by $\mathrm{ON}$ and OFF inputs to RGCs, we recorded puff-evoked ON and OFF EPSCs in RGCs (Fig. 2). CPPG-evoked ON EPSCs ( $V_{\text {hold }}=$ $+40 \mathrm{mV}$ ) were blocked almost completely by the broadspectrum NMDAR antagonist $R, S$-CPP (CPP, $10 \mu \mathrm{M}$; to $8 \pm 6 \%$ of control at $V_{\text {hold }}=+40 \mathrm{mV} ; n=6 ; p=0.01$ ) (Fig. $2 A$ ). Accordingly, a plot of $Q_{\text {EPSC }}$ versus $V_{\text {hold }}$ yielded a J-shaped relation indicating the voltage-dependent block of NMDAR channels by external $\mathrm{Mg}^{2+}$ (Mayer et al., 1984; Nowak et al., 1984) (Fig. 2B). KA-evoked OFF EPSCs also were outwardly rectifying and blocked by CPP (to $5 \pm 8 \%$ of control at $V_{\text {hold }}=+40 \mathrm{mV}$; $n=5 ; p=0.03$ ) (Fig. 2C,D). In both cases, the small, CPPinsensitive component exhibited a linear $Q_{\mathrm{EPSC}}$-voltage relationship (Fig. $2 B, D$ ), consistent with previous work showing that the non-NMDAR component of the EPSC in RGCs is mediated by AMPARs (Lukasiewicz et al., 1997; Chen and Diamond, 2002). Accordingly, the ON EPSC remaining in CPP was blocked by NBQX ( $5 \mu \mathrm{M}$; data not shown). Similar effects of CPP were observed when EPSCs were evoked by brief electrical stimulation $(10 \mu \mathrm{A}$ for $600 \mu \mathrm{s})$ with an electrode placed in the OPL (Fig. $2 E, F)$, indicating that the large fractional NMDAR component was not an artifact of the puff stimulation. CPPG-evoked ON EPSCs recorded at $-70 \mathrm{mV}$ were enhanced by cyclothiazide (50 $\mu \mathrm{M}$ ), which blocks AMPAR desensitization, and were not significantly affected by CPP, confirming that the NMDAR antagonist does not block AMPARs on RGCs (supplemental Fig. 1, available at www.jneurosci.org as supplemental material). The predominant contribution of NMDARs to the $Q_{\mathrm{EPSC}}$ likely reflects the $\sim 50$-fold longer open time of NMDAR channels. These kinetic differences between AMPARs and NMDARs were evident in electrically evoked EPSCs (Fig. 2E) but were obscured during the prolonged, desynchronized release evoked by puff stimulation.

\section{Different NMDAR subtype combinations mediate $\mathrm{ON}$ and OFF EPSCs in RGCs}

NR2 subunits determine several important properties of the NMDAR complex, including its affinity for glutamate and glycine. For example, diheteromeric NMDARs containing NR2B subunits exhibit a 10-fold higher affinity for glycine than those containing NR2A (Priestley et al., 1995). NMDARs at ON and OFF RGC synapses are differentially sensitive to glycine (Lukasiewicz and Roeder, 1995), suggesting that they may comprise distinct NMDAR subtypes. To test this idea, we compared the reduction of ON and OFF EPSCs by Ro 25-6981 (3 $\mu \mathrm{M})$, an NMDAR antagonist exhibiting up to 5000 -fold selectivity for receptors containing the NR2B subunit (Fischer et al., 1997). To permit within-cell comparisons, EPSCs were recorded from ONOFF RGCs that responded strongly to both CPPG and KA. CPPG and KA puffs were delivered to the OPL in alternating sets of 5-10 stimuli in the absence and presence of Ro 25-6981, which reduced ON EPSCs (to $49 \pm 12 \%$ of control; $n=6 ; p=0.03$ ) (Fig. 3A) but exerted no significant effect on OFF EPSCs (to $92 \pm 14 \%$ of control; $n=6$; $p=0.14$ ) (Fig. $3 B$ ). Within individual cells, $\mathrm{ON}$ responses were significantly more sensitive to Ro 25-6981 than were OFF responses $(n=6, p=0.004)$ (Fig. 3C). Ro 25-6981 sensitivity in ON or OFF RGCs (data not shown) was similar to that observed at the analogous input in ON-OFF cells. Although the mechanism by which Ro 25-6981 acts on NMDARs is not completely understood (Fischer et al., 1997), our pharmacological results suggest that ON and OFF inputs to RGCs are mediated by distinct NMDAR subtypes: at ON inputs, a significant fraction of NMDARs appear to contain at least one NR2B subunit, while NR2B NMDARs are largely absent at OFF inputs.

\section{The rod pathway contributes significantly to $\mathrm{ON}$ excitation of CBCs and RGCs}

At bipolar cell ribbon synapses, the synaptic glutamate concentration during an evoked response varies with release probability $\left(P_{\mathrm{r}}\right)$ (Singer et al., 2004). Consequently, modulation of transmitter release would change the glutamate concentration waveform encountered by postsynaptic receptors; because different NMDAR subtypes exhibit distinct affinities for glutamate 

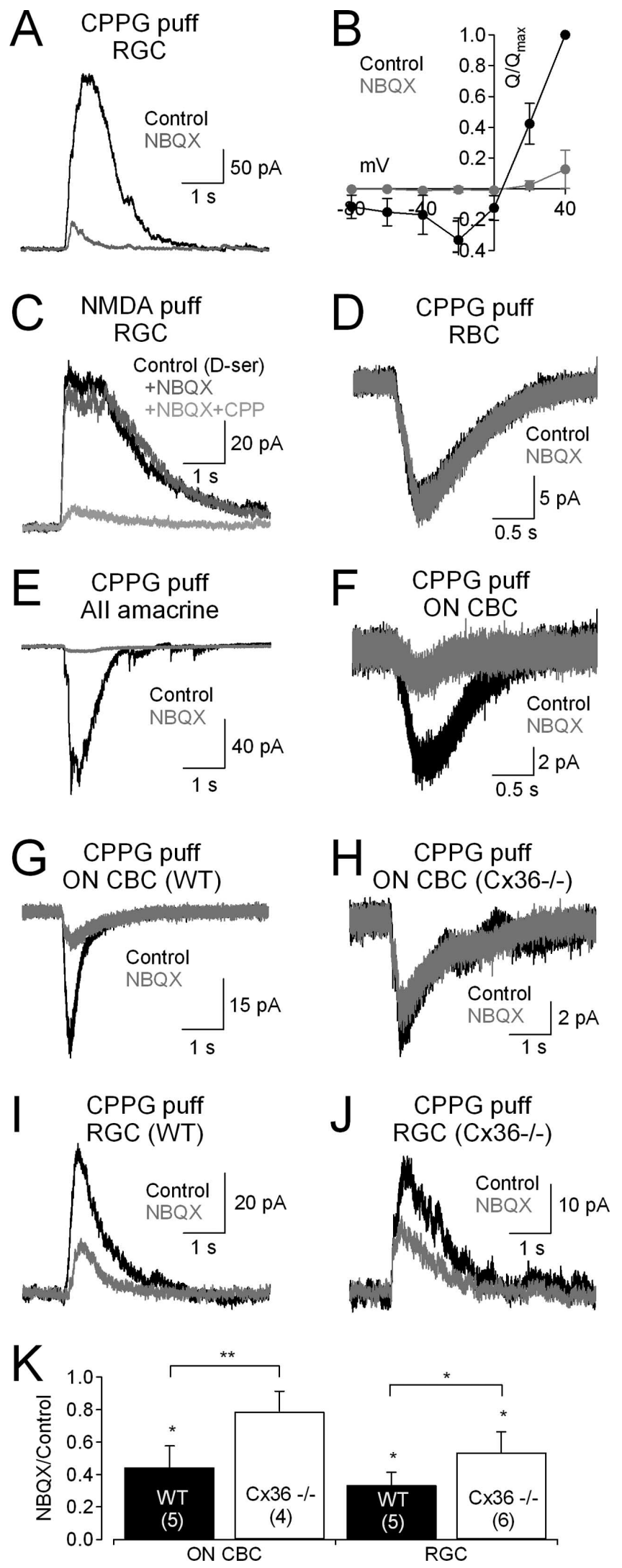

Figure 4. NBQX reduces NMDAR EPSCs by blocking input from the rod pathway. $A$, CPPG evoked EPSCs were reduced by NBQX (5 $\mu \mathrm{m})$. $\boldsymbol{B}$, The NBQX-sensitive component of the EPSC exhibited a J-shaped voltage dependence, indicating that it was mediated primarily by NMDARs. $C$, NBQX does not block NMDARs, as it did not affect responses in RGCs to exogenous NMDA $\left(100 \mu \mathrm{m} ; V_{\text {hold }}=+40 \mathrm{mV}\right) . \boldsymbol{D}$, NBQX did not effect CPPG responses in RBCs, indicating that it did not act on mGluR6. E, NBQX blocked CPPG-evoked EPSCs in All amacrine cells. $F$, NBQX
(Dingledine et al., 1999), this could alter the relative activation of different NMDAR subtypes during the EPSC. To address this possibility at $\mathrm{ON}$ synapses, we took advantage of the fact that CPPG puffs, in addition to stimulating ON CBCs directly, also recruit input to ON CBC terminals from the rod pathway (Fig. $1 \mathrm{~K})$. CPPG-evoked glutamate release from RBCs activates AII amacrine cells (Chávez et al., 2006), which make Connexin36 (Cx36)-containing gap junctions onto ON CBC terminals (Mills et al., 2001; Deans et al., 2002). Blocking excitation of AII amacrine cells with NBQX (Singer and Diamond, 2003; Veruki et al., 2003), then, should decrease transmitter release from ON CBCs onto RGCs. Accordingly, NBQX $(5 \mu \mathrm{M})$ reduced ON EPSCs in RGCs to $13 \pm 11 \%$ of control $(n=5 ; p=0.0006)$ (Fig. $4 A)$. The NBQX-sensitive EPSC was mediated primarily by NMDARs, as it exhibited an outwardly rectifying $Q_{\mathrm{EPSC}}-$ voltage relation (Fig. $4 B$ ). This effect was not due to direct actions of NBQX on NMDARs, as NBQX did not affect responses in RGCs to exogenous NMDA application $(100 \mu \mathrm{M} ; 100 \pm 21 \%$ of control; $n=5$; $p=0.83$ ) (Fig. 4C). Additionally, NBQX did not act directly on mGluR6, as it did not affect CPPG-evoked responses in RBCs $\left(Q_{\text {EPSC }}: 92 \pm 19 \%\right.$ of control; $n=7 ; p=0.19$ ) (Fig. $4 D$ ), which also express mGluR6 (Nomura et al., 1994). NBQX did, however, reduce CPPG-evoked EPSCs in AII amacrine cells $\left(Q_{\mathrm{EPSC}}: 22 \pm\right.$ $17 \%$ of control; $n=5 ; p=0.02$ ) (Fig. $4 E$ ) and ON CBCs (to $24 \pm$ $15 \%$ of control; $n=6 ; p=0.009$ ) (Fig. $4 F$ ). To confirm that the effects in $\mathrm{ON}$ CBCs reflected signal transfer via Cx36 gap junctions between AIIs and ON CBCs, CPPG responses were recorded in wild-type (WT) and Cx36-/- mice (Deans et al., 2002). NBQX reduced CPPG responses in ON CBCs from WT mice (to $44 \pm 9 \%$ of control; $n=5 ; p=0.04$ ) (Fig. 4G,K) but not Cx36- / - mice $(79 \pm 13 \%$ of control; $n=4 ; p=0.18$; WT vs Cx36- $-: p=0.006$ ) (Fig. $4 H, K)$. NBQX reduced ON EPSCs in RGCs of WT mice ( $Q_{\mathrm{EPSC}}: 34 \pm 8 \%$ of control; $\left.n=5 ; p=0.02\right)$ (Fig. $4 I, K)$ more than in Cx36-/- mice $\left(Q_{\mathrm{EPSC}}: 54 \pm 12 \%\right.$ of control; $n=6 ; p=0.007$; WT vs Cx36-l-: $p=0.01$ ) (Fig. $4 \mathrm{~J}, K)$. These results indicate that input from the rod pathway, via AII amacrine cells, contributes significantly to depolarization of ON CBCs and, consequently, ON EPSCs in RGCs.

\section{Activation of $\mathrm{ON}$ pathway modulates occupancy of the} NMDAR coagonist site

NBQX reduced ON EPSCs substantially even in Cx36-/- RGCs (Fig. $4 \mathrm{~K}$ ), suggesting that it may exert other effects within the network to reduce NMDAR activation. One possibility is that NBQX-sensitive receptors drive other cells that release an NMDAR coagonist, either glycine or D-serine, onto RGC NMDARs (Lukasiewicz and Roeder, 1995; Gustafson et al., 2007). For example, both glycinergic amacrine cells and D-serinecontaining Müller glial cells express AMPAR/KARs (Peng et al., 1995; Chávez and Diamond, 2008), rendering them sensitive to NBQX. To test this hypothesis, ON EPSCs were recorded from rat RGCs in the absence and presence of saturating concentrations of D-serine $(100 \mu \mathrm{M})$, a full agonist at the NMDAR coagonist site that is not normally taken up by glycine transporters (Schell et al., 1995) and does not activate strychnine-sensitive glycine receptors (Schmieden et al., 1993). Under normal condi-

strongly reduced CPPG responses in $0 N$ CBCs. $\boldsymbol{G}$, As in $\boldsymbol{F}$, but in a wild-type (WT) mouse ON CBC. $\boldsymbol{H}, \mathrm{NBQX}$ did not affect CPPG responses in ON CBCs from Cx36-I- mice. $\boldsymbol{I}$, NBQX reduced CPPG-evoked EPSCs in RGCs from WT mice. J, NBQX also reduced CPPG-evoked EPSCs in Cx36- / - mice, but to a lesser extent than in WT. $\boldsymbol{K}$, Summarized effects of NBQX on CPPGevoked responses in $\mathrm{ON} C B C s$ and $R G C s . n$ values are indicated in parentheses. 
tions D-serine did not enhance ON EPSCs $\left(Q_{\text {EPSC }}: 103 \pm 22 \%\right.$ of control; $n=6 ; p=$ 0.70 ) (Fig. $5 A$ ), suggesting that NMDAR coagonist sites are saturated during $\mathrm{ON}$ EPSCs. In contrast, ON EPSCs recorded in the presence of NBQX were enhanced by D-serine $\left(Q_{\text {EPSC }}: 253 \pm 79 \%\right.$ of NBQX alone; $n=6 ; p=0.03$ ) (Fig. $5 B$ ), suggesting that NBQX leads to a reduction in coagonist site occupancy during EPSCs. Indeed, NBQX reduced the ON EPSC less in the presence of D-serine $\left(Q_{\mathrm{EPSC}}: 61 \pm 21 \%\right.$ of control; $n=6 ; p=0.01$ ) (Fig. $5 C$ ) than in its absence $\left(Q_{\mathrm{EPSC}}: 13 \pm 10 \%\right.$ of control; $n=6 ; p=0.009 ; p=0.001$ for absence vs presence of D-serine). D-Serine $(100 \mu \mathrm{M})$ did not alter CPPG-evoked EPSCs in AII amacrine cells $\left(Q_{\mathrm{EPSC}}\right.$ : $90 \pm 8.5 \%$ of control, $n=4, p=0.8$ ) (supplemental Fig. $1 C$, available at www.jneurosci.org as supplemental material), indicating that it exerted no significant actions on the Capermeable AMPARs that mediate synaptic inputs to AIIs (Singer and Diamond, 2003). These results suggest that CPPG stimulation of the ON pathway typically evokes coagonist release sufficient to saturate NMDARs, but that blocking AMPARs decreases coagonist release and relieves saturation of the NMDAR coagonist site.

Together, these results suggest that blocking AMPARs reduces NMDAR activation on RGCs via two mechanisms: (1) by blocking activation of AIIs, thereby reducing ON CBC depolarization and consequent glutamate release (Fig. $4 E-K$ ); (2) by reducing release of an NMDAR coagonist, either glycine or D-serine (Fig. $5 A, B)$. Accordingly, NBQX applied in the presence of D-serine reduced the ON EPSC in WT mice but exerted no significant effect on ON EPSCs in Cx36-/- mice (Fig. 5D,E).

Although evoked release appears to saturate the NMDAR coagonist sites (Fig. 5A), it is unclear whether the sites are also saturated by ambient levels of coagonist (Vyklický et al., 1990; Wilcox et al., 1996). To address this issue at ON synapses, we measured the effects of exogenous, saturating concentrations of NMDA and D-serine on holding currents and ON EPSCs in RGCs. Bath application of NMDA $(100 \mu \mathrm{M})$ increased the holding current (to $229 \pm 41 \%$ of control; $n=5 ; p=0.002$ ) (Fig. $5 F$ ) and decreased the evoked ON EPSC (to $39 \pm 24 \%$ of control; $n=$ $5 ; p=0.02)$. Similar effects were observed with $300 \mu \mathrm{M}$ NMDA (data not shown), indicating that $100 \mu \mathrm{M}$ NMDA was sufficient to saturate NMDARs. Subsequent addition of saturating D-serine $(100 \mu \mathrm{M}$ ) further increased the holding current (to $303 \pm 74 \%$ of control; $n=5 ; p=0.02$ ) (Fig. $5 F$ ) and decreased the ON EPSC (to $9 \pm 7 \%$ of control; $n=5 ; p=0.01$ ). The existence of an ON EPSC in the presence of NMDA that is occluded by D-serine confirms that CPPG evokes release of NMDAR coagonist and indicates that NMDARs at ON synapses are not saturated by ambient levels of coagonist.

\section{Coagonist-site occupancy controls NMDAR subtype contribution to ON EPSCs}

The above results demonstrate that NMDAR activation during the ON EPSC is regulated by occupancy of the coagonist site. Because NMDARs containing NR2A versus NR2B subunits have different affinities for glycine (Priestley et al., 1995), changes in coagonist release could modulate the relative contributions of these receptor subtypes. To test this hypothesis, we determined whether changing the amount of available coagonist alters the fractional contribution of NR2B-containing NMDARs to the ON EPSC. In control conditions (i.e., in the absence of NBQX or D-serine), the NR2B antagonist Ro 25-6981 reduced the NMDAR component of ON EPSCs (to $59 \pm 10 \% ; n=6 ; p=0.003$ ) (Fig. $6 A, F$ ), consistent with our previous results in ON-OFF cells (Fig. $3)$. The continuous presence of saturating D-serine did not change the fractional contribution of NR2B-containing receptors $\left(Q_{\mathrm{EPSC}}\right.$ remaining in Ro $25-6981=57 \pm 18 \%$ of $Q_{\mathrm{EPSC}}$ in $\mathrm{D}-$ serine; $n=6 ; p=0.005 ; p=0.84$ vs control) (Fig. $6 B, F$ ), consistent with our earlier finding that evoked coagonist release saturates all NMDARs (Fig. 5A). In the presence of NBQX, which reduces coagonist release (Fig. 5), the block by Ro 25-6981 was significantly enhanced $\left(Q_{\mathrm{EPSC}}\right.$ remaining in Ro 25-6981 = $26 \pm$ $11 \%$ of $Q_{\mathrm{EPSC}}$ in NBQX; $n=6 ; p=0.02 ; p=0.0003$ vs control) (Fig. 6C,F). This was due to a reduction in coagonist site occupancy, because in the continuous presence of both $\mathrm{D}$-serine and NBQX, the block by Ro 25-6981 was similar to that in control conditions (to $57 \pm 27 \%$ of $Q_{\mathrm{EPSC}}$ in D-serine $+\mathrm{NBQX} ; n=7$; $p=0.03 ; p=0.93$ vs control) (Fig. $6 D, F)$. These results indicate that reducing coagonist release from an AMPAR-driven cell (or cells) limits the activation of non-NR2B NMDARs in favor of higher-affinity, NR2B-containing subtypes.

NMDARs are not necessarily saturated by synaptically released glutamate (Mainen et al., 1999; McAllister and Stevens, 2000; Ishikawa et al., 2002; Pankratov and Krishtal, 2003). It is possible, therefore, that modulating glutamate release from $\mathrm{ON}$ CBCs could alter the relative activation of different NMDARs independently of coagonist binding. As mentioned above, because a single ribbon can release multiple vesicles within a millisecond, the peak glutamate concentration sensed by receptors opposing the ribbon synapses of bipolar cells varies with $P_{\mathrm{r}}$ 

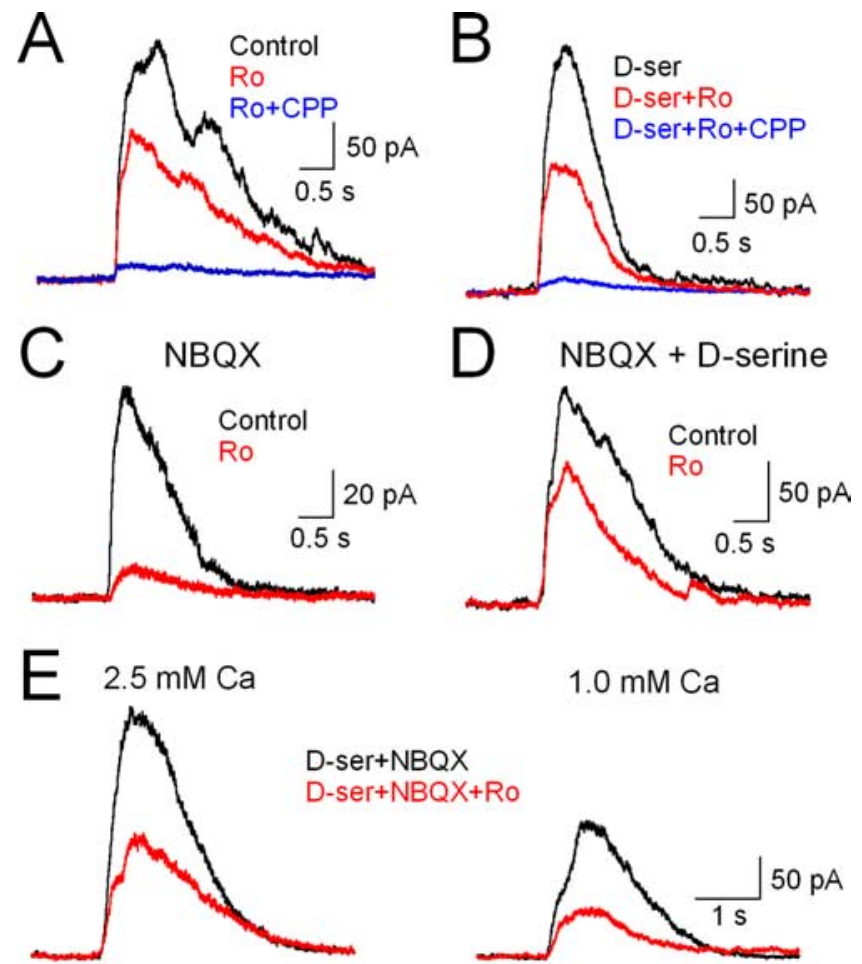

$1.0 \mathrm{mM} \mathrm{Ca}$

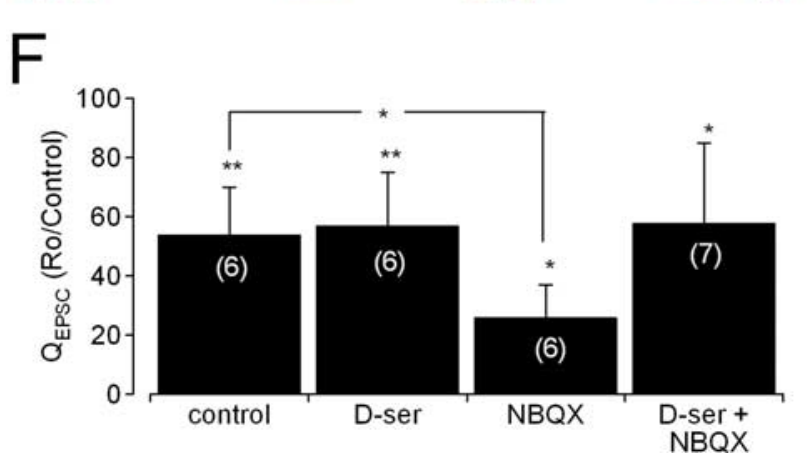

Figure 6. Synaptic release of coagonist modulates relative contribution of different NMDAR subtypes to the EPSC. $V_{\text {hold }}=+40 \mathrm{mV}$ in all experiments. $A$, CPPG-evoked EPSCs were reduced by the NR2B NMDAR antagonist Ro 25-6981 (3 $\mu \mathrm{m}$ ). $\boldsymbol{B}$, Ro 25-6981 exerted similar effects in the presence of D-serine (100 $\mu \mathrm{M})$. $C$, In the presence of NBQX, Ro 25-6981 blocked a larger fraction of the CPPG-evoked EPSC. D , The increased effect of Ro 25-6981 was eliminated in the presence of the NMDAR coagonist D-serine. $\boldsymbol{E}$, Ro 25-6981 reduced CPPG-evoked EPSC 5 to similar extents in $2.5 \mathrm{~mm}$ and $1.0 \mathrm{~mm} \mathrm{Ca}^{2+}$. Recordings are from the same cell in the continuous presence of 5 $\mu \mathrm{M}$ NBQX and $100 \mu \mathrm{m}$ D-serine. $\boldsymbol{F}$, Effects of Ro 25-6981 on EPSCs under different pharmacological conditions. $n$ values are indicated in parentheses.

(Singer et al., 2004). If the activation of relatively low-affinity (i.e., non-NR2B) NMDARs at ON inputs to RGCs is particularly limited by the synaptic glutamate concentration, then decreasing $P_{\mathrm{r}}$ may increase the fractional block of the EPSC by an NR2Bspecific antagonist. To test this hypothesis, ON EPSCs were evoked in the presence of saturating D-serine (to negate possible effects of changing $P_{\mathrm{r}}$ on coagonist release) and NBQX. Under these conditions, reducing external $\mathrm{Ca}^{2+}$ from $2.5 \mathrm{~mm}$ to $1.0 \mathrm{mM}$ significantly decreased the ON EPSC (to $61 \pm 19 \% ; n=7 ; p=$ 0.02), but the degree of block by Ro 25-6981 was unchanged [2.5 mM Ca: Ro reduced $Q_{\text {EPSC }}$ to $60 \pm 22 \%$ of control, $n=7 ; p=$ 0.02; $1.0 \mathrm{mM} \mathrm{Ca}$ : Ro reduced $Q_{\mathrm{EPSC}}$ to $63 \pm 23 \%, n=7, p=0.02$; Ro block in 2.5 vs $1.0 \mathrm{~mm} \mathrm{Ca:} p=0.57$ (paired)] (Fig. 6E). This result suggests that modulation of coagonist release, but not glutamate release, affects relative NMDAR subunit contributions to CPPG-evoked EPSCs.
Endogenous D-serine contributes to ambient occupancy of the coagonist site

The data presented thus far indicate that evoked coagonist release contributes to NMDAR activation during ON EPSCs. Is the coagonist glycine, D-serine, or some combination of the two? Glycine is an obvious candidate, because half the amacrine cells in the inner retina use glycine as their primary neurotransmitter (MacNeil and Masland, 1998; Menger et al., 1998). On the other hand, recent reports suggest that $\mathrm{D}$-serine acts as an endogenous coagonist for NMDARs in several regions of the CNS, including the retina (Martina et al., 2003; Panatier et al., 2006; Gustafson et al., 2007), where Müller glial cells express D-serine and its synthetic enzyme, serine racemase (Stevens et al., 2003). [D-Serine expression in RGCs, evident in newborn mice, is significantly diminished by the third postnatal week (Dun et al., 2008).] We also detected immunoreactivity for both $\mathrm{D}$-serine and serine racemase in $\mathrm{P} 17$ and $\mathrm{P} 21$ rat retina (Fig. 7A-D). Colocalization of D-serine with glutamine synthetase, a Müller cell marker (Riepe and Norenburg, 1977), was particularly strong at P22 (Fig. 7C2), but neuronal expression of $\mathrm{D}$-serine and serine racemase was evident at both ages.

To evaluate whether D-serine contributes to NMDAR activation at $\mathrm{ON}$ inputs, we tested the effects of $\mathrm{D}$-amino acid oxidase (DAAO; $100 \mu \mathrm{g} / \mathrm{ml}$ ), an enzyme that degrades D-serine but not glycine (Dixon and Kleppe, 1965; Molla et al., 2006), on CPPGevoked ON EPSCs. Perfusion with DAAO for a minimum of 20 min decreased ON EPSCs (to $72 \pm 10 \%$ of control; $n=6 ; p=$ 0.02 ) (Fig. 7E). This reduction could reflect a decrease in the amount of ambient coagonist and/or a decrease in evoked coagonist release during the EPSC. To distinguish these two possibilities, we tested the effects of DAAO on ON EPSCs in the continuous presence of NMDA (Fig. $7 F$ ). DAAO reduced the steadystate holding current at $+40 \mathrm{mV}$ (from $335 \pm 153 \mathrm{pA}$ to $201 \pm 98$ $\mathrm{pA} ; n=6 ; p=0.01)$ but had no effect on the amplitude of the evoked ON EPSC ( $110 \pm 90 \%$ of NMDA alone; $n=6 ; p=0.69)$. Although effects of DAAO on the evoked response could be diminished due to saturation of the coagonist site by evoked release of glycine or incomplete elimination of D-serine, these results suggest that D-serine contributes more to ambient coagonist site occupancy rather than activation during an evoked response.

To test this idea further, we examined the effects of DAAO on the NMDAR subunit contribution to the ON EPSC. Experiments shown in Figure 6 indicated that NBQX changes the relative contribution of NR2B NMDARs to the ON EPSC by modulating coagonist occupancy: NR2B NMDARs mediated a larger fraction of the EPSC when coagonist release was reduced, an effect that was reversed with the addition of saturating coagonist (Fig. $6 C, D, F)$. These results suggest that NR2B NMDARs have a different (higher) affinity for released coagonist than other NMDARs. In functional studies comparing coagonist affinity in recombinant diheteromeric NR1/NR2A and NR1/NR2B NMDARs, NR2B NMDARs exhibited a 10-fold higher affinity for glycine than did NR2A NMDARs, while affinity for D-serine was similar between the two subtypes (Priestley et al., 1995). Consistently, in the presence of DAAO, the NR2B antagonist Ro 256981 blocked the ON EPSC to a similar extent $\left(Q_{\mathrm{EPSC}}\right.$ reduced to $49 \pm 17 \%$ of control; $n=6 ; p=0.03$ ) as in the absence of DAAO $\left(Q_{\mathrm{EPSC}}\right.$ reduced to $59 \pm 10 \% ; n=6 ; p=0.003$; Ro effect with vs without DAAO: $p=0.23$ ) (Fig. $7 G$ ). Thus, a reduction in D-serine release alone cannot explain the effects of NBQX on coagonist site occupancy. These results suggest that D-serine and glycine play complementary roles in contributing to NMDAR activation in RGCs. 

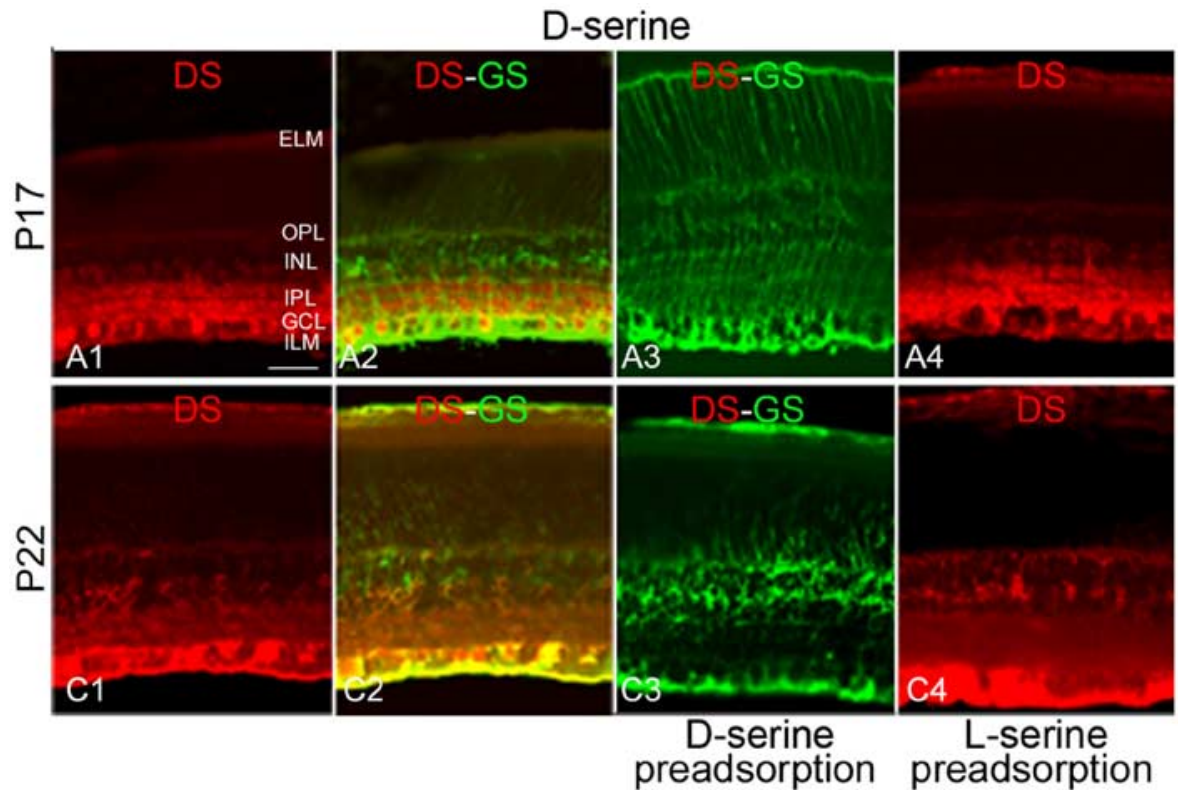

\section{(1)}

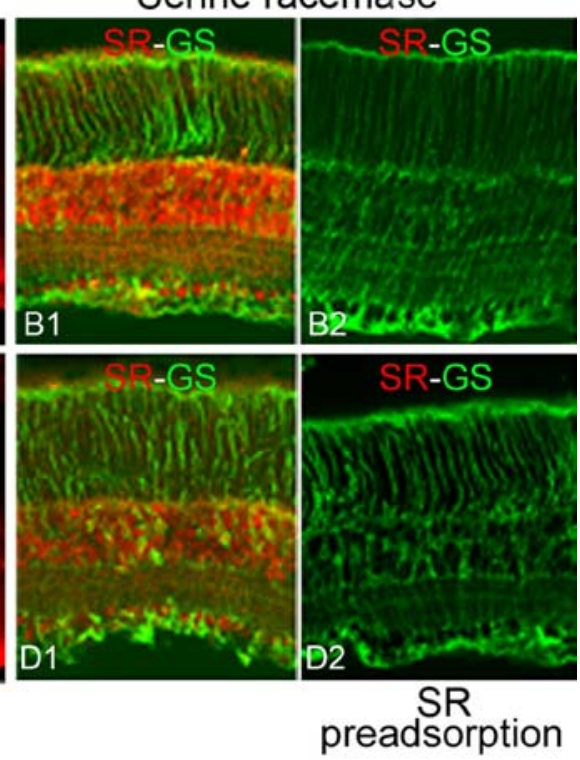

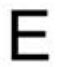

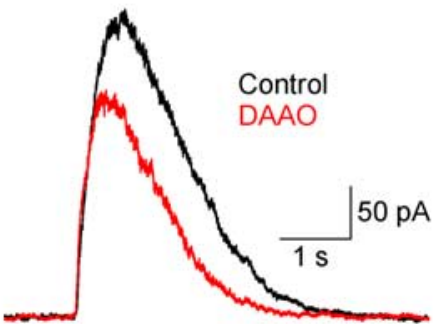

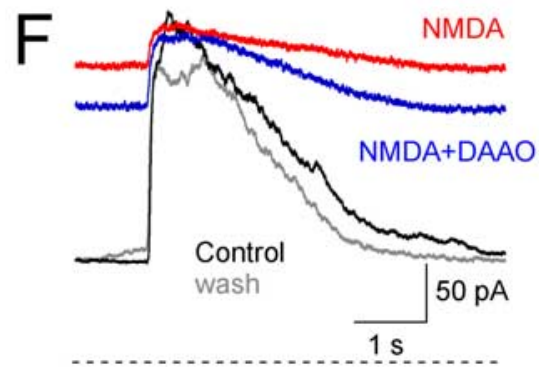

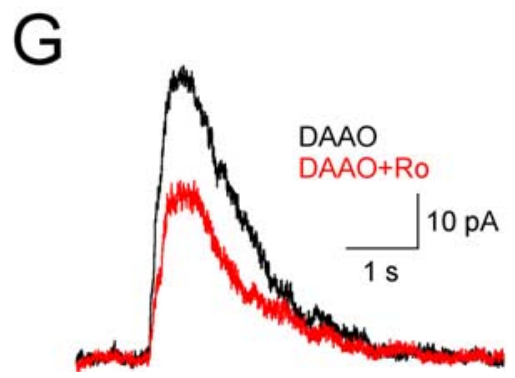

Figure 7. D-Serine and glycine play complementary roles in activating NMDARs. A, Immunoreactivity (IR) for D-serine (DS) in P17 rat retina. DS IR was evident in the inner plexiform layer (IPL), the ganglion cell layer (GCL), the inner nuclear layer (INL) and the outer plexiform layer (OPL; $\boldsymbol{A}$ 1) and was colocalized with glutamine synthetase (GS), a Müller cell marker (A2). ELM, External limiting membrane; ILM, internal limiting membrane. DS IR was eliminated by preadsorption of DS (A3) but not L-serine (A4). $\boldsymbol{B}$, Serine racemase (SR) IR in P17 rat retina. SR IR was evident primarily in the INL and GCL (B1), but no SR IR was detected following preadsorption with SR antigen peptide (B2). $\boldsymbol{C}$, As in $\boldsymbol{A}$ but in P22 retina. DS IR was weaker in the IPL and stronger in the ELM and ILM compared with P17. D, As in $\boldsymbol{B}$ but in P22 retina. Scale bar in $\boldsymbol{A} \mathbf{1}(50 \mu \mathrm{m})$ applies to $\boldsymbol{A}-\boldsymbol{D}$. E, Degradation of D-serine with DAA0 $(100 \mu \mathrm{g} / \mathrm{ml})$ reduced CPPG-evoked EPSCs. F, Exogenous NMDA increased holding current and decreased CPPG-evoked EPSCs (red trace, $V_{\text {hold }}=+40 \mathrm{mV}$ ). In the presence of NMDA, DAAO reduced the holding current but not the EPSC (blue trace). The gray trace indicates both NMDA and DAAO washed out. The dashed line indicates zero holding current. G, Ro 25-6981 reduced CPPG-evoked EPSCs in the presence of DAA0.

\section{Discussion}

The results presented here provide several new pieces of information about synaptic activation of NMDARs on RGCs in the retina. ON inputs to RGCs use NMDARs exhibiting NR2B-like pharmacology to a much greater extent than do OFF inputs (Fig. 3). Moreover, synaptic activation of the retinal circuitry evokes the release of NMDAR coagonist (Fig. 5), which contributes to receptor activation during ON EPSCs and, in fact, modulates the relative contribution of different NMDAR subtypes (Fig. 6). Our results suggest that both $\mathrm{D}$-serine and glycine act as endogenous NMDAR coagonists on RGCs (Fig. 7), a hybrid arrangement reflecting the prominence of both transmitters in the retinal circuitry (Fig. 8).

In this study, ON and OFF pathways were selectively activated by puff application of CPPG and KA to the OPL. Sensitivity to this exogenous stimulation was tightly correlated to light responsivity (Fig. 1). Notably, within-cell comparisons of responses to puff and light stimulation indicated that, at least in juvenile (P17P23) rats, a functional continuum exists between "ON," "ONOFF," and "OFF" RGCs (Fig. 1J). This may reflect ongoing activity-dependent developmental pruning of RGC dendrites that gradually reduces the fraction of ON-OFF RGCs through the end of the fourth postnatal week (Tian and Copenhagen, 2003).

\section{ON and OFF inputs to RGCs activate distinct NMDAR subtypes}

NMDARs mediate synaptic input to RGCs in every species studied to date (Mittman et al., 1990; Matsui et al., 1998; Chen and Diamond, 2002; Sagdullaev et al., 2006), but specific functions for NMDARs, or roles for different NMDAR subtypes in RGC signaling, have not been identified. Here we show in rat RGCs that ON and OFF inputs use distinct NMDAR subunit combinations (Fig. 8), analogous to recent results in other CNS neurons that receive inputs from multiple, functionally distinct pathways. For example, CA1 pyramidal neurons in the hippocampus receive perforant path input via synapses that contain a larger fraction of NR2B NMDARs than those mediating Schaffer collateral input (Kawakami et al., 2003; Arrigoni and Greene, 2004). In neocortical pyramidal cells, the comparatively slow kinetics of NR2B NMDARs underlies input-specific differences in EPSP integration (Kumar and Huguenard, 2003). In the retina, specific physiological roles for particular NMDAR subtypes in the ON and OFF pathways remain to be determined, but our results contribute to an emerging pattern of asymmetries in the $\mathrm{ON}$ and OFF inputs to RGCs (Chichilnisky and Kalmar, 2002; Sagdullaev et al., 2006). One possibility is that the differential expression of lowand high-affinity subtypes may offset pathway-specific differ- 


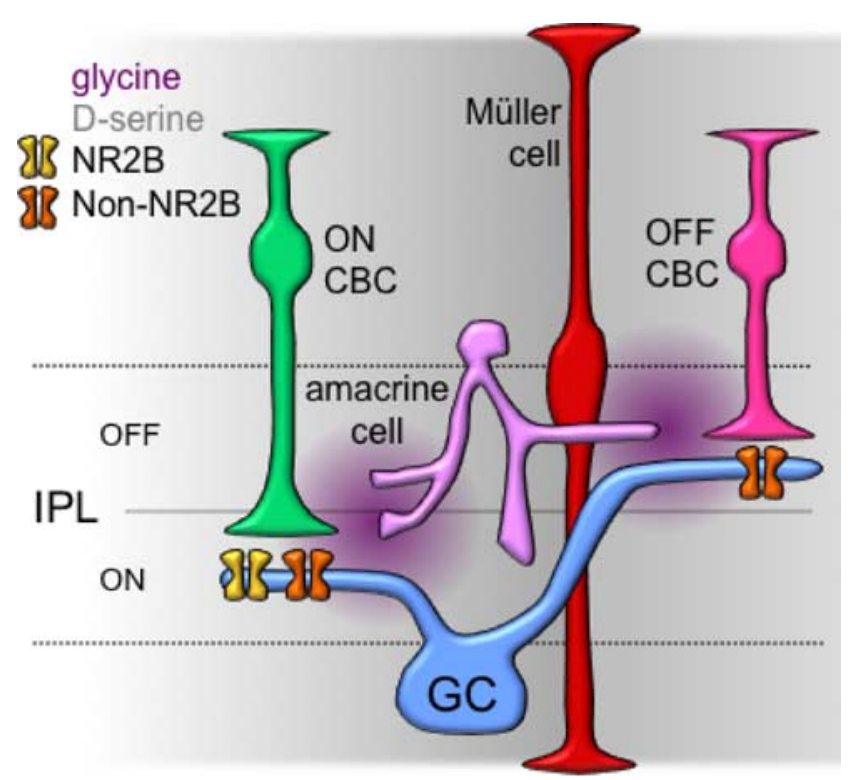

Figure 8. Multiple NMDARs and coagonists in the inner retina. Simplified schematic illustrating distinct NMDAR subtypes at ON and OFF synapses onto RGCS (GC). ON synapses contain NR2B and non-NR2B NMDARs, and OFF synapses express primarily non-NR2B NMDARs (see Fig. 3). D-Serine (gray), perhaps released diffusely from Müller glial cells, may contribute primarily to ambient coagonist site occupancy. Glycine (violet), likely released from amacrine cells, may increase coagonist site occupancy during evoked responses.

ences in synaptic availability of coagonist to maintain similar levels of NMDAR activation at $\mathrm{ON}$ and OFF inputs. Activation of non-NR2B NMDARs, which have relatively low affinity for glycine (Priestley et al., 1995), may require higher glycine levels that may exist in the OFF sublamina, where AII amacrine cells release glycine directly onto OFF bipolar cell terminals (Kolb, 1979), while higher-affinity NR2B NMDARs predominate in the ON layers of the IPL, where glycinergic inputs are more scarce (Pow and Hendrickson, 2000).

Another possibility is that distinct expression of different NR2 subunits reflects either a cause or a consequence of the developmental segregation of the ON and OFF sublamina (Tian and Copenhagen, 2003). In other parts of the CNS, the appearance of particular NR2 subunits correlates with distinct developmental stages. For example, synapses in the neonatal hippocampus express primarily NR2B-containing receptors, until NR2Acontaining receptors appear during the second postnatal week (Monyer et al., 1994; Kutsuwada et al., 1996), when they are incorporated into the postsynaptic density, possibly as a necessary step in activity-dependent synaptic maturation (Bellone and Nicoll, 2007). Additionally, distinct NMDAR subtype expression may trigger differences in dendritic branching density, analogous to a recent report in developing Xenopus tectal neurons (Ewald et al., 2008). Expansive developmental studies of NR2 subunit expression, physiological activation and dendritic modeling in RGCs are required to address whether the onset or cessation of expression of particular NMDAR subtypes in RGCs contributes to dendritic segregation between, and branching within, functional layers of the IPL. Finally, it should be noted that, because the mechanism by which NR2B-selective antagonists Ro 25-6981 and ifenprodil act on NMDARs is incompletely understood ( $\mathrm{Fi}$ scher et al., 1997), immunoelectron microscopy will be required to confirm the existence of NR2B-containing receptors at ON synapses (J. Zhang and J. S. Diamond, unpublished work).

\section{Coagonist release from within the retinal circuitry modulates} NMDAR activation

When it was first discovered that NMDAR activation required a coagonist in addition to glutamate, the coagonist was presumed to be glycine (Johnson and Ascher, 1987). Given the paucity of glycinergic transmission in most forebrain regions, it was generally assumed that the coagonist site was bound by ambient glycine, which is present in CSF at concentrations several times higher than its $\mathrm{EC}_{50}$ at the coagonist site (Ferraro and Hare, 1985; Johnson and Ascher, 1987). Accordingly, the coagonist site generally was thought to be saturated (Llano et al., 1988; Bashir et al., 1990; Mothet et al., 2000), despite several counterexamples (e.g., Forsythe et al., 1988; Thomson et al., 1989; D'Angelo et al., 1990; Lester et al., 1993). Previous work in salamander retina suggested that glycine released from amacrine cells can reach NMDARs on RGCs (Lukasiewicz and Roeder, 1995), but the issue of ambient saturation was not addressed. Here, we isolated synaptic activation of the NMDAR coagonist site by eliciting EPSCs in the presence of saturating concentrations of NMDA (Fig. 5I). The EPSCs evoked under these conditions, therefore, reflect synaptic release of coagonist and successful activation of the coagonist site. This is consistent with previous work showing that coagonist released from within the retinal network contributes to NMDAR activation on RGCs (Lukasiewicz and Roeder, 1995; Stevens et al., 2003; Gustafson et al., 2007), and it represents the first direct demonstration that synaptic stimulation elicits coagonist release to activate NMDARs.

In this decade, $\mathrm{D}$-serine has emerged as a likely endogenous NMDAR coagonist in several brain regions (Mothet et al., 2000; Panatier et al., 2006), including the retina (Stevens et al., 2003; Gustafson et al., 2007). D-Serine and its synthetic enzyme, serine racemase, are found in glial cells in the hippocampus, supraoptic nucleus, and retina (Mothet et al., 2000; Stevens et al., 2003; Panatier et al., 2006). Although D-serine and serine racemase expression in the rodent retina decreases during development (Dun et al., 2008), functional expression is still evident in adult rat retina (Stevens et al., 2003), and it was clearly present at the ages studied here (Fig. 7). In the supraoptic nucleus, physiological modulation of the physical juxtaposition of synapses and surrounding glial processes, which release D-serine, regulates NMDAR activation and synaptic plasticity (Panatier et al., 2006). Interestingly, in that case, modulating the effective synaptic concentration of D-serine affected NMDAR EPSC amplitude without changing the relative contribution of NR2B and non-NR2B NMDARs, both of which were activated by synaptic stimulation (Panatier et al., 2006). This is consistent with pharmacological studies of recombinant NMDARs in a heterologous expression system indicating that NR2B and NR2A NMDARs exhibit similar affinity for D-serine (Priestley et al., 1995). In contrast, NR2B NMDARs exhibit a 10-fold higher affinity for glycine compared with NR2A NMDARs (Priestley et al., 1995). Our observation that reducing coagonist release favors activation of NR2B NMDARs (Fig. 6) argues, then, that synaptically released glycine activates NMDARs in the ON pathway. Our results also indicate, however, that D-serine contributes to NMDAR activation, as reported in salamander retina (Stevens et al., 2003; Gustafson et al., 2007). Our observation that D-serine degradation decreases ambient NMDAR activation without affecting evoked responses (Fig. 7) is consistent with a scenario in which D-serine released from Müller glia, perhaps in a diffuse manner characteristic of many modulatory neurotransmitters, contributes to ambient, submaximal occupancy of the coagonist site, while the transient, synaptic release of glycine from amacrine cells contributes to 
NMDAR activation during EPSCs (Fig. 8). These contrasting roles may reflect, in part, the avid uptake of glycine in the retinal circuitry (Pow and Hendrickson, 2000), which may cause glycine to be more tightly regulated than $\mathrm{D}$-serine and limit its action to evoked synaptic events. An interesting, unresolved question concerns whether amacrine cells release glycine at excitatory synapses, or if NMDARs are activated by glycine spillover from nearby inhibitory synapses, as in the spinal cord (Ahmadi et al., 2003).

\section{References}

Ahmadi S, Muth-Selbach U, Lauterbach A, Lipfert P, Neuhuber WL, Zeilhofer HU (2003) Facilitation of spinal NMDA receptor currents by spillover of synaptically released glycine. Science 300:2094-2097.

Arrigoni E, Greene RW (2004) Schaffer collateral and perforant path inputs activate different subtypes of NMDA receptors on the same CA1 pyramidal cell. Br J Pharmacol 142:317-322.

Bashir ZI, Tam B, Collingridge GL (1990) Activation of the glycine site in the NMDA receptor is necessary for the induction of LTP. Neurosci Lett 108:261-266.

Bellone C, Nicoll RA (2007) Rapid bidirectional switching of synaptic NMDA receptors. Neuron 55:779-785.

Brandstätter JH, Hartveit E, Sassoè-Pognetto M, Wässle H (1994) Expression of NMDA and high-affinity kainate receptor subunit mRNAs in the adult rat retina. Eur J Neurosci 6:1100-1112.

Chávez AE, Diamond JS (2008) Diverse mechanisms underlie glycinergic feedback transmission onto rod bipolar cells in rat retina. J Neurosci 28:7919-7928.

Chávez AE, Singer JH, Diamond JS (2006) Fast neurotransmitter release triggered by Ca influx through AMPA-type glutamate receptors. Nature 443:705-708.

Chen S, Diamond JS (2002) Synaptically released glutamate activates extrasynaptic NMDA receptors on cells in the ganglion cell layer of rat retina. J Neurosci 22:2165-2173.

Chichilnisky EJ, Kalmar RS (2002) Functional asymmetries in ON and OFF ganglion cells of primate retina. J Neurosci 22:2737-2747.

D’Angelo E, Rossi P, Garthwaite J (1990) Dual-component NMDA receptor currents at a single central synapse. Nature 346:467-470.

Deans MR, Volgyi B, Goodenough DA, Bloomfield SA, Paul DL (2002) Connexin36 is essential for transmission of rod-mediated visual signals in the mammalian retina. Neuron 36:703-712.

Dingledine R, Borges K, Bowie D, Traynelis SF (1999) The glutamate receptor ion channels. Pharmacol Rev 51:7-61.

Dixon M, Kleppe K (1965) D-Amino acid oxidase. 3. Effect of pH. Biochim Biophys Acta 96:383-389.

Dun Y, Duplantier J, Roon P, Martin PM, Ganapathy V, Smith SB (2008) Serine racemase expression and D-serine content are developmentally regulated in neuronal ganglion cells of the retina. J Neurochem 104:970-978.

Ewald RC, Van Keuren-Jensen KR, Aizenman CD, Cline HT (2008) Roles of NR2A and NR2B in the development of dendritic arbor morphology in vivo. J Neurosci 28:850-861.

Ferraro TN, Hare TA (1985) Free and conjugated amino acids in human CSF: influence of age and sex. Brain Res 338:53-60.

Fischer G, Mutel V, Trube G, Malherbe P, Kew JN, Mohacsi E, Heitz MP, Kemp JA (1997) Ro 25-6981, a highly potent and selective blocker of $\mathrm{N}$-methyl-D-aspartate receptors containing the NR2B subunit. Characterization in vitro. J Pharmacol Exp Ther 283:1285-1292.

Fletcher EL, Hack I, Brandstätter JH, Wässle H (2000) Synaptic localization of NMDA receptor subunits in the rat retina. J Comp Neurol 420:98-112.

Forsythe ID, Westbrook GL, Mayer ML (1988) Modulation of excitatory synaptic transmission by glycine and zinc in cultures of mouse hippocampal neurons. J Neurosci 8:3733-3741.

Gründer T, Kohler K, Kaletta A, Guenther E (2000) The distribution and developmental regulation of NMDA receptor subunit proteins in the outer and inner retina of the rat. J Neurobiol 44:333-342.

Grünert U, Haverkamp S, Fletcher EL, Wässle H (2002) Synaptic distribution of ionotropic glutamate receptors in the inner plexiform layer of the primate retina. J Comp Neurol 447:138-151.

Gustafson EC, Stevens ER, Wolosker H, Miller RF (2007) Endogenous
D-serine contributes to NMDA-receptor-mediated light-evoked responses in the vertebrate retina. J Neurophysiol 98:122-130.

Ishikawa T, Marsala M, Sakabe T, Yaksh TL (2000) Characterization of spinal amino acid release and touch-evoked allodynia produced by spinal glycine or GABA(A) receptor antagonist. Neuroscience 95:781-786.

Ishikawa T, Sahara Y, Takahashi T (2002) A single packet of transmitter does not saturate postsynaptic glutamate receptors. Neuron 34:613-621.

Johnson JW, Ascher P (1987) Glycine potentiates the NMDA response in cultured mouse brain neurons. Nature 325:529-531.

Kawakami R, Shinohara Y, Kato Y, Sugiyama H, Shigemoto R, Ito I (2003) Asymmetrical allocation of NMDA receptor epsilon2 subunits in hippocampal circuitry. Science 300:990-994.

Kolb H (1979) The inner plexiform layer in the retina of the cat: electron microscopic observations. J Neurocytol 8:295-329.

Kumar SS, Huguenard JR (2003) Pathway-specific differences in subunit composition of synaptic NMDA receptors on pyramidal neurons in neocortex. J Neurosci 23:10074-10083.

Kutsuwada T, Sakimura K, Manabe T, Takayama C, Katakura N, Kushiya E, Natsume R, Watanabe M, Inoue Y, Yagi T, Aizawa S, Arakawa M, Takahashi T, Nakamura Y, Mori H, Mishina M (1996) Impairment of suckling response, trigeminal neuronal pattern formation, and hippocampal LTD in NMDA receptor epsilon 2 subunit mutant mice. Neuron 16:333-344.

Lester RA, Tong G, Jahr CE (1993) Interactions between the glycine and glutamate binding sites of the NMDA receptor. J Neurosci 13:1088-1096.

Llano I, Marty A, Johnson JW, Ascher P, Gähwiler BH (1988) Patch-clamp recording of amino acid-activated responses in "organotypic" slice cultures. Proc Natl Acad Sci U S A 85:3221-3225.

Lukasiewicz PD, Roeder RC (1995) Evidence for glycine modulation of excitatory synaptic inputs to retinal ganglion cells. J Neurosci 15:4592-4601.

Lukasiewicz PD, Wilson JA, Lawrence JE (1997) AMPA-preferring receptors mediate excitatory synaptic inputs to retinal ganglion cells. J Neurophysiol 77:57-64.

Lynch DR, Anegawa NJ, Verdoorn T, Pritchett DB (1994) N-methyl-Daspartate receptors: different subunit requirements for binding of glutamate antagonists, glycine antagonists, and channel-blocking agents. Mol Pharmacol 45:540-545.

MacNeil MA, Masland RH (1998) Extreme diversity among amacrine cells: implications for function. Neuron 20:971-982.

Mainen ZF, Malinow R, Svoboda K (1999) Synaptic calcium transients in single spines indicate that NMDA receptors are not saturated. Nature 399:151-155.

Martina M, Krasteniakov NV, Bergeron R (2003) D-Serine differently modulates NMDA receptor function in rat CA1 hippocampal pyramidal cells and interneurons. J Physiol 548:411-423.

Matsui K, Hosoi N, Tachibana M (1998) Excitatory synaptic transmission in the inner retina: paired recordings of bipolar cells and neurons of the ganglion cell layer. J Neurosci 18:4500-4510.

Mayer ML, Westbrook GL, Guthrie PB (1984) Voltage-dependent block by $\mathrm{Mg} 2+$ of NMDA responses in spinal cord neurones. Nature 309:261-263.

McAllister AK, Stevens CF (2000) Nonsaturation of AMPA and NMDA receptors at hippocampal synapses. Proc Natl Acad Sci USA 97:6173-6178.

Menger N, Pow DV, Wässle H (1998) Glycinergic amacrine cells of the rat retina. J Comp Neurol 401:34-46.

Mills SL, O'Brien JJ, Li W, O'Brien J, Massey SC (2001) Rod pathways in the mammalian retina use connexin 36. J Comp Neurol 436:336-350.

Mittman S, Taylor WR, Copenhagen DR (1990) Concomitant activation of two types of glutamate receptor mediates excitation of salamander retinal ganglion cells. J Physiol 428:175-197.

Molla G, Sacchi S, Bernasconi M, Pilone MS, Fukui K, Polegioni L (2006) Characterization of human D-amino acid oxidase. FEBS Lett 580:2358-2364.

Monyer H, Burnashev N, Laurie DJ, Sakmann B, Seeburg PH (1994) Developmental and regional expression in the rat brain and functional properties of four NMDA receptors. Neuron 12:529-540.

Mothet JP, Parent AT, Wolosker H, Brady RO Jr, Linden DJ, Ferris CD, Rogawski MA, Snyder SH (2000) D-serine is an endogenous ligand for the glycine site of the N-methyl-D-aspartate receptor. Proc Natl Acad Sci U S A 97:4926-4931. 
Nawy S (2004) Desensitization of the mGluR6 transduction current in tiger salamander On bipolar cells. J Physiol 558:137-146.

Nomura A, Shigemoto R, Nakamura Y, Okamoto N, Mizuno N, Nakanishi S (1994) Developmentally regulated postsynaptic localization of a metabotropic glutamate receptor in rat rod bipolar cells. Cell 77:361-369.

Nowak L, Bregestovski P, Ascher P, Herbet A, Prochiantz A (1984) Magnesium gates glutamate-activated channels in mouse central neurones. $\mathrm{Na}-$ ture 307:462-465.

Panatier A, Theodosis DT, Mothet JP, Touquet B, Pollegioni L, Poulain DA, Oliet SH (2006) Glia-derived D-serine controls NMDA receptor activity and synaptic memory. Cell 125:775-784.

Pankratov YV, Krishtal OA (2003) Distinct quantal features of AMPA and NMDA synaptic currents in hippocampal neurons: implication of glutamate spillover and receptor saturation. Biophys J 85:3375-3387.

Peng YW, Blackstone CD, Huganir RL, Yau KW (1995) Distribution of glutamate receptor subtypes in the vertebrate retina. Neuroscience 66:483-497.

Pow DV, Hendrickson AE (2000) Expression of glycine and the glycine transporter glyt-1 in the developing rat retina. Vis Neurosci 17:1-9.

Priestley T, Laughton P, Myers J, Le Bourdellés B, Kerby J, Whiting PJ (1995) Pharmacological properties of recombinant human $N$-methyl-Daspartate receptors comprising NR1a/NR2A and NR1a/NR2B subunit assemblies expressed in permanently transfected mouse fibroblast cells. Mol Pharmacol 48:841-848.

Riepe RE, Norenburg MD (1977) Muller cell localisation of glutamine synthetase in rat retina. Nature 268:654-655.

Sagdullaev BT, McCall MA, Lukasiewicz PD (2006) Presynaptic inhibition modulates spillover, creating distinct dynamic response ranges of sensory output. Neuron 50:923-935.

Schell MJ, Molliver ME, Snyder SH (1995) D-serine, an endogenous synaptic modulator: localization to astrocytes and glutamate-stimulated release. Proc Natl Acad Sci U S A 92:3948-3952.

Schmieden V, Kuhse J, Betz H (1993) Mutation of glycine receptor subunit creates beta-alanine receptor responsive to GABA. Science 262:256-258.
Singer JH, Diamond JS (2003) Sustained $\mathrm{Ca}^{2+}$ entry elicits transient postsynaptic currents at a retinal ribbon synapse. J Neurosci 23:10923-10933.

Singer JH, Lassová L, Vardi N, Diamond JS (2004) Coordinated multivesicular release at a mammalian ribbon synapse. Nat Neurosci 7:826-833.

Stevens ER, Esguerra M, Kim PM, Newman EA, Snyder SH, Zahs KR, Miller RF (2003) D-serine and serine racemase are present in the vertebrate retina and contribute to the physiological activation of NMDA receptors. Proc Natl Acad Sci U S A 100:6789-6794.

Thomson AM, Walker VE, Flynn DM (1989) Glycine enhances NMDAreceptor mediated synaptic potentials in neocortical slices. Nature 338:422-424.

Tian N, Copenhagen DR (2003) Visual stimulation is required for refinement of ON and OFF pathways in postnatal retina. Neuron 39:85-96.

Tovar KR, Westbrook GL (1999) The incorporation of NMDA receptors with a distinct subunit composition at nascent hippocampal synapses in vitro. J Neurosci 19:4180-4188.

Veruki ML, Mørkve SH, Hartveit E (2003) Functional properties of spontaneous EPSCs and non-NMDA receptors in rod amacrine (AII) cells in the rat retina. J Physiol 549:759-774.

Vyklický L Jr, Benveniste M, Mayer ML (1990) Modulation of N-methyl-Daspartic acid receptor desensitization by glycine in mouse cultured hippocampal neurones. J Physiol 428:313-331.

Watanabe M, Mishina M, Inoue Y (1994) Differential distributions of the NMDA receptor channel subunit mRNAs in the mouse retina. Brain Res 634:328-332.

Werblin FS (1978) Transmission along and between rods in the tiger salamander retina. J Physiol 280:449-470.

Wilcox KS, Fitzsimonds RM, Johnson B, Dichter MA (1996) Glycine regulation of synaptic NMDA receptors in hippocampal neurons. J Neurophysiol 76:3415-3424.

Zhang J, Diamond JS (2006) Distinct perisynaptic and synaptic localization of NMDA and AMPA receptors on ganglion cells in rat retina. J Comp Neurol 498:810-820. 